\title{
Preoperative Level of Serum CA- 125 in Patient with Ovarian Cancer
}

Dr. Jannatul Ferdous ${ }^{1 *}$, Dr. Goury Prava Dhar ${ }^{2}$, Dr. Mahbubur Rahman ${ }^{3}$, Dr. Mohammad Mostafizur Rahman ${ }^{4}$

${ }^{1}$ Associate Professor, Department of Gynae \& Obstetric, Ashiyan Medical College Hospital, Barua Khilkhet, Dhaka, Bangladesh

${ }^{2}$ Faculty, Evolution Health Academy, Miami Garden, Florida-33169, USA

${ }^{3}$ Associate Professor, Department of Gynae \& Obstetric, OSD, DGHS, Mohakhali, Dhaka Attached with Patuakhali, Medical College, Patuakhali, Bangladesh

${ }^{4}$ Assistant Professor \& Head, Dept. of Anesthesiology \& ICU, Ashiyan Medical College Hospital, Barua Khilkhet, Dhaka, Bangladesh

DOI: $10.36347 /$ sjams.2020.v08i09.023

| Received: 07.09.2020 | Accepted: 16.09.2020 | Published: 19.09.2020

*Corresponding author: Dr. Jannatul Ferdous

Abstract

Original Research Article

Introduction: Ovarian cancer is an alarming health problem in Bangladesh. The annual morality rate per 1, 00,000 people from ovarian cancer in Bangladesh has raised by $40.3 \%$ since 1990, an average of $1.8 \%$ per year. Globcan predicts changes in the reported incidence of ovarian cancer from 2912 in year 2012 to 3132 to 2015 . Recurrent highgrade ovarian cancer is usually associated with short term survival. Disease stage at diagnosis is a strong prognostic variable for predicting patient outcome in ovarian cancer. Aim of the study: to investigate the histological characteristics and stage of ovarian cancer and to correlate with preoperative level of serum CA -125. Material \& Methods: This cross sectional study was carried out at the Department of Obstetrics and Gynaecology in Ashiyan Medical College Hospital, Barua Khilkhet, and Dhaka, Bangladesh during the period from August 2018 to July 2019. A total of 100 patients were selected using purposive sampling technique for this study. Data were collected and documented on a preformed and pretested structured questionnaire. Clinical examination and relevant investigation were done and recorded accordingly. Data were processed and analyzed with the help of computer software SPSS 22. Results: Mean age of the study subjects was $45.7 \pm 15.2$ years with a range of 13-75 years. Table II shows education status of the study subjects. It was observed that half of the study subjects had education up to primary level, $26 \%$ had studied up to secondary level, $19 \%$ up to higher secondary level and only 5\% were graduate. Mean BMI was $23.3 \pm 3.0$ $\mathrm{kg} / \mathrm{m}^{2}$, mean age of marriage was $16.1 \pm 2.8$ years and mean CA-125 level was 547.02 \pm 478.74. Maximum study subjects had stage III $(44.0 \%)$ followed by stage II (24.0\%), stage I (21. 0\%) and stage IV (11.0\%). Also, most of the study subjects had serous tumors $(70.0 \%)$ followed by mucinous tumors $(11.0 \%)$, endometrioid adenocarcinoma $(8.0 \%)$, clear cell tumors (4.0\%), malignant tertoma (5.0\%), Brenner (1.0\%) and dysgerminoma (1.0\%). Endometrioid adenocarcinoma was found in elderly study subjects and clear cell tumor was found in young aged study subjects. Histopathological type according to grading of ovarian tumor describes, all stage IV tumors were serous, all clear cell and Brenner tumors were stage I, and all endometrioid adenocarcinoma tumors were stage III. Serum CA-125 was elevated at the advanced stage of ovarian cancer. Conclusion: Serum CA-125 had significant positive correlation with surgical stage of ovarian cancer in epithelial cancer patients of this study. But in case of germ cell ovarian cancer it showed a negative correlation.

Keywords: Ovarian cancer, Histological Characteristics, Stage of Ovarian Cancer, Serum CA -125.

Copyright @ 2020: This is an open-access article distributed under the terms of the Creative Commons Attribution license which permits unrestricted use, distribution, and reproduction in any medium for non-commercial use (NonCommercial, or CC-BY-NC) provided the original author and source are credited.

\section{INTRODUCTION}

Ovarian cancer is an alarming health problem in Bangladesh. The annual morality rate per 1, 00,000 people from ovarian cancer in Bangladesh has raised by $40.3 \%$ since 1990, an average of $1.8 \%$ per year. Globcan predicts changes in the reported incidence of ovarian cancer from 2912 in year 2012 to 3132 to 2015. Recurrent high- grade ovarian cancer is usually associated with short term survival [1]. Disease stage at diagnosis is a strong prognostic variable for predicting patient outcome in ovarian cancer. Patients with
International Federation of Gynaecology and obstetrics (FIGO) stage II ovarian cancer, indicating tumor dissemination and seeding of the peritoneal lining outside of the pelvis, have s 5 - year's survival rate of approximately $35 \%$. This survival rate decrease to less than $10 \%$ in patients diagnosed with stage IV ovarian cancer, where disease had spread to distant metastasis [2]. Therefore, early detection and appropriate management prevent the fetal outcome of ovarian cancer. Ovarian carcinomas related to highest death rate in gynecological malignancies as absence of symptoms shield the disease in the early stage. Current evidences 
have been devoted to discovering early effective screening mechanism before the onset of clinical symptoms. Therefore, biomarkers are the important tools that are capable of fight against this deadly disease [3]. The history of biomarkers and Ultrasonography dates back over more than 50 years. The present status of biomarkers used in the context of ovarian cancer is addressed. Importance is given to new interpretations of the etiology of ovarian cancer [4]. CA- 125 is a glycoprotein first described on 1981. It is a tumour marker of ovarian malignancy and it is derived from both coelomic and mullerian epithelial. It is approved by US FDA. It has two major antigen domain components; they are OC 125 and M11. CA-125 is a biomarker that has potential utility across the spectrum: for risk assessment, early detection, diagnosis, prognosis, monitoring and therapy. Overall sensitivity of serum CA -125 levels to cytohistological expression is $100 \%$ and the specificity is $86 \%$ with positive and negative predictive value of $74 \%$ and $100 \%$ respectively [5]. Although another study reported, preoperative CA125 levels do not correlate well with FIGO staging [6]. CA -125 is tumour marker, commonly, used for screening ovarian cancer. However, recent studies have proven a limited role for CA- 125 as a diagnostic marker for ovarian cancer. CA- 125 level $35 \mathrm{U} / \mathrm{ml}$ is considering as the cut -off value when evaluating serum CA -125 ovarian cancers [5]. An immature teratoma is very rare tumor, representing $1 \%$ of all teratomas, $1 \%$ of all ovarian cancers, and $35.6 \%$ of malignant ovarian germ cell tumors [7]. It displays a specific age of incidence, occurring most frequently in the first two decades of life and almost never after menopause [8]. Unlike a mature cystic teratomas, an immature teratoma contains immature or embryonic structures. It can coexist with mature cystic teratomas and can constitute of a combination of both adult and embryonic tissue [9]. The most common symptoms noted are abdominal distension and masses. Prognosis and treatment options vary and largely depend on grade, stage and karyotype of the tumor itself. Whenever malignancy is suspected, a staging laparotomy should be carried out. The importance of thorough surgical staging cannot be over emphasized because subsequent treatment will be determined by the stage of the disease. Therefore, we have investigated the histological characteristics and stage of ovarian cancer and have correlated with preoperative level of serum CA -125 . We also tried to find out role of CA-125 in identifying different stages of ovarian cancer.

\section{MeTHODS}

This cross sectional study was carried out at the Department of Obstetrics and Gynaecology in Ashiyan Medical College Hospital, Barua Khilkhet, and
Dhaka, Bangladesh during the period from August 2018 to July 2019. A total of 100 patients were selected using purposive sampling technique for this study. Data were collected and documented on a preformed and pretested structured questionnaire. Clinical examination and relevant investigation were done and recorded accordingly. Data were processed and analyzed with the help of computer software SPSS 22. P value $<0.05$ was considered as statistical significant. Patients' blood sample was drawn from the antecubital vein. 5 milliliters blood was drawn with proper aseptic precautions. The blood sample was transferred into a clean, dry test tube and taken to the labouratory. Blood sample was centrifuged for 10 minutes at a rate of 4000rmp. Statistical analysis was done by SPSS software version-22.

\section{RESULTS}

Table I shows age distribution of the study subjects. Maximum (33.3\%) study subjects were $\leq 30$ years old followed by age group $41-50$ years $(27.2 \%)$, $31-40$ years $(24.4 \%)$ and $>50$ years $(14.8 \%)$. Mean age of the study subjects was $45.7 \pm 15.2$ years with a range of 13-75 years. Table II shows education status of the study subjects. It was observed that half of the study subjects had education up to primary level, $25.6 \%$ had studied up to secondary level, $18.5 \%$ up to higher secondary level and only $4.9 \%$ were graduate. Table III shows occupation of study subjects. Maximum study subjects were housewife $(67.9 \%)$, followed by $16 \%$ teacher, $7.4 \%$ service holder, $4.9 \%$ student and $3.7 \%$ tailor. Mean BMI was $23.3 \pm 3.0 \mathrm{~kg} / \mathrm{m}^{2}$, mean age of marriage was $16.1 \pm 2.8$ years and mean CA-125 level was 547.02 478.74 (Table IV). Table V shows surgical stages of ovarian cancer of the study subjects. Maximum study subjects had stage III (44.4\%) followed by stage II (23.5\%), stage I (21. $0 \%)$ and stage IV (11.1\%). Table VI shows histopathological finding of the tumors. Maximum study subjects had serous tumors $(70.4 \%)$ followed by mucinous tumors $(11.1 \%)$, endometrioid adenocarcinoma $(7.4 \%)$, clear cell tumors $(3.7 \%)$, malignant tertoma (4.9\%), Brenner $(1.2 \%)$ and dysgerminoma (1.2\%). Table VII shows association of age with histopathological findings. Endometrioid adenocarcinoma was found in elderly study subjects and clear cell tumor was found in young aged study subjects. Table VIII shows histopathological type according to grading of ovarian tumor that describes, all stage IV tumors were serous, all clear cell and Brenner tumors were stage I, and all endometrioid adenocarcinoma tumors were stage III. Table IX shows preoperative serum CA-125 level at different surgical stage of ovarian cancer among the study subjects. Serum CA-125 was elevated at the advanced stage of ovarian cancer. 
Table-I: Age distribution of the study subjects $(n=100)$

\begin{tabular}{|l|l|l|}
\hline Age (years) & Frequency $(\boldsymbol{\%})$ & $\boldsymbol{\%}$ \\
\hline$\leq 30$ & 27 & 33.3 \\
\hline $31-40$ & 20 & 24.4 \\
\hline $41-50$ & 22 & 27.2 \\
\hline$>50$ & 12 & 14.8 \\
\hline Mean \pm SD & $45.7 \pm 15.2(13-75)$ & \\
\hline
\end{tabular}

Table-II: Distribution of education status of study subjects. $(n=100)$

\begin{tabular}{|l|l|l|}
\hline Education & Frequency $\mathbf{( \% )}$ & $\mathbf{\%}$ \\
\hline Primary & 41 & 50.6 \\
\hline Secondary & 21 & 25.6 \\
\hline Higher Secondary & 15 & 18.5 \\
\hline Graduate & 4 & 4.9 \\
\hline
\end{tabular}

Table-III: Distribution of occupational status of study subjects. $(\mathrm{n}=100)$

\begin{tabular}{|l|l|l|}
\hline Occupation & Frequency & \% \\
\hline Housewife & 55 & 67.9 \\
\hline Teacher & 13 & 16.0 \\
\hline Service holder & 5 & 7.4 \\
\hline Student & 4 & 4.9 \\
\hline Tailor & 3 & 3.7 \\
\hline
\end{tabular}

Table-IV: BMI, age of marriage and mean CA-125 level of the study subjects $(n=100)$.

\begin{tabular}{|l|l|l|}
\hline Parameters & Mean \pm SD & Min - max \\
\hline BMI $\left(\mathrm{kg} / \mathrm{m}^{2}\right)$ & $23.3 \pm 3.0$ & $17-28.4$ \\
\hline $\begin{array}{l}\text { Age of marriage } \\
\text { (years) }\end{array}$ & $16.1 \pm 2.8$ & $12-15$ \\
\hline CA-125 & $547.02 \pm 478.74$ & $24-1600$ \\
\hline
\end{tabular}

Table-V: Distribution of study subjects according to surgical stage of ovarian cancer. $(\mathrm{n}=100)$.

\begin{tabular}{|l|l|l|}
\hline $\begin{array}{l}\text { Surgical stages of } \\
\text { ovarian Cancer }\end{array}$ & Frequency & $\%$ \\
\hline I & 17 & 21.0 \\
\hline II & 19 & 23.5 \\
\hline III & 36 & 44.4 \\
\hline IV & 9 & 11.1 \\
\hline
\end{tabular}

Table-VI: Distribution of study subjects by histopathological type of ovarian cancer. $(\mathrm{n}=100)$

\begin{tabular}{|c|c|c|}
\hline Type of tumor & Frequency & $\%$ \\
\hline \multicolumn{3}{|l|}{ Epithelial } \\
\hline Mucinous tumors & 9 & 11.1 \\
\hline Serous tumor & 57 & 70.4 \\
\hline Clear cell tumors & 3 & 3.7 \\
\hline Endrometrioid adenocarcinoma & 6 & 7.4 \\
\hline Brenner & 1 & 1.2 \\
\hline \multicolumn{3}{|l|}{ Germ cell } \\
\hline Dygerminoma & 1 & 1.2 \\
\hline Malignant teratoma & 4 & 4.9 \\
\hline
\end{tabular}


Table-VII: Histopathological type of ovarian cancer with their mean age of study subjects. $(n=100)$

\begin{tabular}{|l|l|}
\hline Type of tumor & Mean \pm SD Age (years) \\
\hline Epithelial \\
\hline Mucinous tumors & $51.56 \pm 21.87$ \\
\hline Serous tumor & $47.74 \pm 11.10$ \\
\hline Clear cell tumors & $16.67 \pm 2.52$ \\
\hline Endrometrioid adenocarcinoma & $57.50 \pm 8.21$ \\
\hline Brenner & $35.00 \pm 0.00$ \\
\hline Germ cell \\
\hline Dygerminoma & $30.00 \pm 0.00$ \\
\hline Malignant teratoma & $17.25 \pm 3.10$ \\
\hline
\end{tabular}

Table-VIII: Distribution of study subjects by histopathological findings and relation with stage of ovarian cancer.

\begin{tabular}{|l|l|l|l|l|}
\multicolumn{5}{|c|}{$(\mathbf{n}=100)$} \\
\hline \multirow{5}{*}{ Histopathological type of tumor } & Stage I & Stage II & Stage III & Stage IV \\
\cline { 2 - 5 } & $\mathrm{n}(\%)$ & & \\
\hline Epithelial & $3(17.6)$ & $3(16.8)$ & $3(8.3)$ & $0(0.0)$ \\
\hline Mucinous tumors & $7(41.2)$ & $16(84.2)$ & $25(69.4)$ & $9(100.0)$ \\
\hline Serous tumor & $3(17.6)$ & $0(0.0)$ & $0(0.0)$ & $0(0.0)$ \\
\hline Clear cell tumors & $0(0.0)$ & $0(0.0)$ & $6(16.6)$ & $0(0.0)$ \\
\hline Endrometrioid adenocarcinoma & $1(5.9)$ & $0(0.0)$ & $0(0.0)$ & $0(0.0)$ \\
\hline Brenner & $0(0.0)$ & $0(0.0)$ & $1(2.8)$ & $0(0.0)$ \\
\hline Germ cell & $3(17.6)$ & $0(0.0)$ & $1(2.8)$ & $0(0.0)$ \\
\hline Dygerminoma & & & \\
\hline Malignant teratoma &
\end{tabular}

Table-IX: Preoperative serum CA -125b level of different surgical stages of ovarian cancer among the study subjects $(\mathbf{n}=100)$

\begin{tabular}{|l|l|l|}
\hline Surgical stage of ovarian cancer & Serum CA-125(mean \pm SD) & P \\
\hline I & $247.18 \pm 149.28$ & \multirow{2}{*}{$<0.001$} \\
\cline { 1 - 2 } II & $449.26 \pm 79.33$ & \\
\hline III & $505.97 \pm 481.40$ & \\
\hline IV & $1484.00 \pm 101.34$ & \\
\hline
\end{tabular}

\section{DISCUSSION}

CA 125 antigen is a cell membrane glycoprotein expressed by various types of epithelial cells and it is present in patients with a variety of cancers namely breast, endometrium, gastrointestinal tract, and lung in addition to the ovarian cancer (OC) as well as in benign diseases of the uterus, liver, and gastrointestinal tract and benign tumors of the ovary and uterus [10]. In present study, maximum (33.3\%) study subjects were $\leq 30$ years old followed by age group 41- 50 years (27.2\%), 31- 40 years $(24.4 \%)$ and $>50$ years $(14.8 \%)$. Mean age of study subjects was almost similar in the study of Nayak et al.[6] found mean age $47.5 \pm 10.2$ year. Bai et al.[11] found mean age of the ovarian clear cell carcinoma patients was $50.8 \pm 10.7 \%$ years with range of $23-85$ years. Present study showed almost half of this study population having primary education and maximum study subjects were housewife $(68 \%)$. Mean BMI was $23.3 \pm 3.0 \mathrm{~kg} / \mathrm{m}^{2}$ and mean age of marriage was $16.1 \pm 2.8$ years. There is evidence that have established obesity to be associated with enhanced ovarian cancer risk through a hormonal mechanism. ${ }^{12}$ In present study, maximum study subjects had had stage III (44.4\%) followed by stage II (23.5\%), stage I (21. 0\%) and stage IV (11.1\%). Previous study done by Nayak et al. [6] showed similar result like (46.2\%) had stage III disease. In the study of Bai et al.[11] stage I was $45.0 \%$, stage II was $11.5 \%$, stage III was $35.2 \%$ and stage IV was $5.3 \%$. Furrer et al.[13] also found maximum stage III Patients (61.0\%) followed by stage I (21.0\%), stage II (12.0\%) and stage IV $(6.0 \%)$. In another study, preoperative CA-125 was $>35 \mathrm{U} / \mathrm{ml}$ in $73(90.1 \%)$ cases. Preoperative CA-125 was elevated $(>35 \mathrm{U} / \mathrm{ml})$ in majority $(78.9 \%)$ of patients [11]. CA-125 was $>35 \mathrm{U} / \mathrm{ml}$ in $77.8 \%$ cases in the study of Pradjatmo. Jiang et al.[14] suggested a cut-off point of $25 \mathrm{IU} / \mathrm{ml}$ for preoperative CA-125 serum levels, whereas Choi et al.[15] recommended a cut-off point of $30 \mathrm{IU} / \mathrm{ml}$ for extra-uterine disease and $50 \mathrm{IU} / \mathrm{ml}$ for lymph node metastasis, respectively. Hsieh $e t$ al. [16] established that raised CA-125 levels preoperatively had noteworthy correlation with lymph node metastasis, unconventional stage, complexity of assault and cervical invasion with a cut-off point of 40 $\mathrm{IU} / \mathrm{ml}$, and can be well thought-out for full pelvic lymphadenectomy. 
Serum CA -125 was elevated at the advanced stage of ovarian cancer. Similar finding also observed in the study of Furrer et al.[13] Patients who have high preoperative serum CA 125 levels may be candidates for comprehensive surgical staging of endometrial cancer as well as lymphadenectomy[17-19]. Surgical methods range from hysterectomy single-handedly for all patients, hysterectomy with lymphadenectomy reliant on the surgeon's criteria for threat of nodal metastasis based on preoperative grading or intraoperative assessment, hysterectomy with limited lymphadenectomy, or hysterectomy with full pelvic and para-aortic lymphadenectomy for all patients. ${ }^{20}$ Present study showed histopathological distribution of the ovarian cancers, like serous tumors $(70.4 \%)$, mucinous tumors $(11.1 \%)$, endometrioid adenocarcinoma (7.4\%), malignant teratoma $(4.9 \%)$ and clear cell tumors (3.7\%). Furrer et al.[13] found serous tumors (65.0\%), clear cell tumors $(12.0 \%)$, Endometrioid tumors $(13.0 \%)$, mucinous tumors $(5.0 \%)$, undifferentiated carcinoma $(2.0 \%)$ and mixed malignant mullerian tumors $(3.0 \%)$. In the study of Morimoto et al.[21] serous was $79.0 \%$, Adenocarcinoma was $50.0 \%$, carcinoma was $4.0 \%$, endometrioid was $2.0 \%$ and mucinous was $1.0 \%$. Most common tumor was serous adenocarcinoma (23.0\%) in the study of Nayak et al.[6] Present study Serum CA-125 had significant positive correlation with surgical stage of ovarian cancer in epithelial cancer patients. But in case of germ cell ovarian cancer it showed a negative correlation. Unlike our study, Nayak et al.[6] did not find any correlation of CA -125 with stages of ovarian cancer. This could be because he did the correlation for all histopathological tumour together. Preoperative serum tumor marker CA125 levels are a useful indication of the disease [22].

\section{LIMITATIONS OF THE STUDY}

The present study was conducted at a very short period of time. For being a study in a single community with comparatively small number of sample size, the study result may not reflect the exact scenarios of the mass people.

\section{CONCLUSION AND \\ RECOMMENDATIONS}

A preoperative dimension of serum CA 125 is essential for women with endometrial cancer since it can be cast-off in preoperative choices concerning the level of surgery and the usage of adjuvant treatment to offer the optimal consequence. In our study, serum CA125 had significant positive correlation with surgical stage of ovarian cancer in epithelial cancer patients. But in case of germ cell ovarian cancer it showed a negative correlation. However, multicenter study should be done with large sample size for a longer duration. Moreover, other cofactors which might have an influence on stage of ovarian cancer should be evaluated.

\section{REFERENCES}

1. Hoque ME, Karim S, Siddiqui MMR. and Ahmed T. Reported on Three Cases of Advance Ovarian Cancer Upon Bangladeshi population: Successful Management with Bevacizumab Based Chemotherapy. Anwer Khan Modern Medical College Journal. 2017;8(2): 157 - 61 .

2. Coticchia CM, Yang $\mathrm{J}$ and Moses MA. Ovarian cancer biomarkers: current potions and future promise. Journal of the National Comprehensive cancer Network. 2008; 6(8): 795-802.

3. Muinao T, Deka Boruah HP, Pal M. Diagnostic and Prognostic Biomarkers in ovarian cancer and the potential roles of cancer stem cells - An updated review. Exp Cell Res. 2018;362(1):1-10.

4. Ueland, F.R. A Perspective on Ovarian Cancer Biomarkers: Past, Present and Yet-To-Come. Diagnostics. 2017, 7, 14.

5. Das C, Mukhopadhyay M, Ghosh T, Saha AK and Sengupta M. Correlation of cytohistlogical expression and serum level of cal 125 in ovarian neoplasm . Journal of clinical and Diagnostic Research: JCDR. 2014; 8(3): 41-43.

6. Nayak. Using a Systems Pharmacology Model of the Blood Coagulation Network to Predict the Effects of Various Therapies on Biomarkers. CPT Pharmacometrics Syst Pharmacol. 2015 Jul; 4(7): 396-405.

7. Alwazzan AB, Popowich S, Dean E, Robison C, Lotocki $\mathrm{R}$ and Altman AD. Pure immature teratoma of the ovary in adults: thirty -years' experience of a single tertiary care center. International Journal of Gynecologic cancer. 2015; 25(9): 1616-22.

8. Di Saia PJ and Creasmam WT. Clinical gynecologic oncology. 8th ed., Philadelphia: Elsevier Saunders.2012.

9. Coran A, Caldamone A and Adzick NS. Pediatric surgery 7th ed., Philadelphia: Elsevier Mosby. 2012.

10. Fritsche HA and Bast RC. CA 125 in ovarian cancer. Advances and controversy. Clinical chemistry. 1998; 44:1379 - 80 .

11. Bai H, Sha G, Xiao M, Gao H, Cao D, Yang J, Wang Y, Zhang Z and Shen K. The prognostic value of pretreatment CA 125 levels and CA -125 normalization in ovarian clear cell carcinoma: a two- academic -institute study. Oncotarget. 2016; 7(13), 155-66.

12. Michael F. Leitzmann, Corinna Koebnick, Kim N. Danforth, Louise A. Brinton, Steven C. Moore, Albert R. Hollenbeck, Arthur Schatzkin, and James V. Lacey, Jr., 2009. Body mass index and risk of ovarian cancer. Cancer. 2009 Feb 15; 115(4): 812-822.

13. Furrer D, Gregoire J, Turcotte S, Plante $M$, Bachvarov D, Trudel D, Tetu B, Douville P and Bairati I. Performance of preoperative plasma tumor markers HE4 and CA 125 in predicting ovarian cancer mortality in women with 
epithelial ovarian cancer. PloSone. 2019; 14(6): $2186-97$.

14. Jiang T, Huang L, Zhang S. Preoperative serum CA125: a useful marker for surgical management of endometrial cancer. BMC Cancer. 2015; 15:396.

15. Choi YS, Koh SB, Ahn JY. Usefulness of preoperative CA 125 level in decision making of lymphadenectomy in endometrial cancer patients. Korean J Obstet Gynecol. 2005;48(12):2877-87.

16. Hsieh CH, ChangChien CC, Lin H. Can a preoperative CA 125 level be a criterion for full pelvic lymphadenectomy in surgical staging of endometrial cancer? Gynecol Oncol. 2002;86(1):28-33.

17. Mariani A, Dowdy SC, Cliby WA, Haddock MG, Keeney GL, Lesnick TG. Efficacy of systemic lymphadenectomy and adjuvant radiotherapy in node positive endometrial cancer patients. Gynecol Oncol. 2006; 101:200-8.

18. Bristow RE, Zahurak ML, Alexander CJ, Zellars RC, Montz FJ. FIGO stage IIIC endometrial carcinoma: resection of macroscopic nodal disease and other determinants of survival. Int $\mathbf{J}$ Gynecol Cancer. 2003; 13:664-72.

19. Cragun JM, Havrilesky LJ, Calingaert B, Synan I, Secord AA, Soper JT. Retrospective analysis of selective lymphadenectomy in apparent early-stage endometrial cancer. J Clin Oncol. 2005; 23:366875.

20. Pecorelli S. Revised FIGO staging for carcinoma of the vulva, cervix, and endometrium. Int J Gynecol Obstet. 2009; 105:103-4.

21. Morimoto A. A preoperative low cancer antigen 125 level $(\leq 25.8 \mathrm{mg} / \mathrm{dl})$ is a useful criterion to determine the optimal timing of interval debulking surgery following neoadjuvant chemotherapy in epithelial ovarian cancer. Jpn J Clin Oncol. 2016;46(6):517-521.

22. Fures R, Bukovic D, Hodek B, Klaric B, Herman R and Grubisic G. Preoperative tumor marker CA 125 levels in relation to epithelial ovarian cancer. Collegium Antropologicum. 1999; 23(1): 189 - 94. 